\title{
MICROSEISMICITY AND SEISMOTECTONIC PROPERTIES OF THE LEFKADA - KEFALONIA SEISMIC ZONE
}

\author{
Karakostas, V. G. ${ }^{1}$, Papadimitriou, E. E. ${ }^{1}$, Karamanos Ch. K. ${ }^{1}$ \\ and Kementzetzidou, D.A.1 \\ ${ }^{1}$ Aristotle University of Thessaloniki, School of Geology, Department of Geophysics, 54124 Thessaloniki, \\ Greece,vkarak@geo.auth.gr,ritsa@geo.auth.gr,chrikar@geo.auth.gr,dkementz@auth.gr
}

\begin{abstract}
Microseismicity, focal-mechanisms, and previously-published focal parameter data are used to determine the current tectonic activity of the prominent zone of seismicity in Lefkada and Kefalonia Islands. Recordings from a local network installed and operated on the two Islands, as well as from permanent stations there, were used to obtain accurate microseismicity locations, which in turn is exploited to reveal properties of smaller localized active structures and the large-scale crustal faulting. The microseismicity substantially agrees with the historic seismicity and delineates a relatively narrow, major zone of activity that extends along the western coasts of both Islands. Cross sections were used in order to provide a detailed characterization of the microseismicity and a high-resolution picture of the seismically defined structures. For the investigation of the past seismic activity relocation of the hypocenters of older events was performed, using a reliable velocity model and time delays for the regional stations, calculated on the basis of the accurately determined focal parameters using the local recordings. The yielding location improvement contributes to the geometry identification of the active structures, which were previously obscured by location errors, and which constitute a critical input for the study area seismic hazard assessment.
\end{abstract}

Key words: microseismicity, relocation, active structures, Ionian Islands.

\section{Introduction}

Local scale earthquake location studies of small magnitude earthquakes lend insight into seismogenic zone processes and are well suited to define the geometry and volume of the seismogenic zones and to constrain their thickness along strike and downdip. Detailed investigation of the local seismicity in the area of the central Ionian Islands, the most active in Greece and its surroundings, is then demanded, which is expected to add information to the location of active faulting and their characteristics. The 2003 Lefkada sequence provided for first time the proper data for a detailed look at the properties of the dominant rupture system (Karakostas et al., 2004), as well as on the activation of secondary structures capable to produce additional and severe damage, thus posing significant seismic hazard (Karakostas, 2008; Karakostas and Papadimitriou, 2010). These findings demonstrated the need for a detailed analysis of earthquake occurrence and faulting, which in turn requires the accurate knowledge of the precise spatial location of earthquake hypocenters, especially in the case of offshore or smaller secondary faults. 


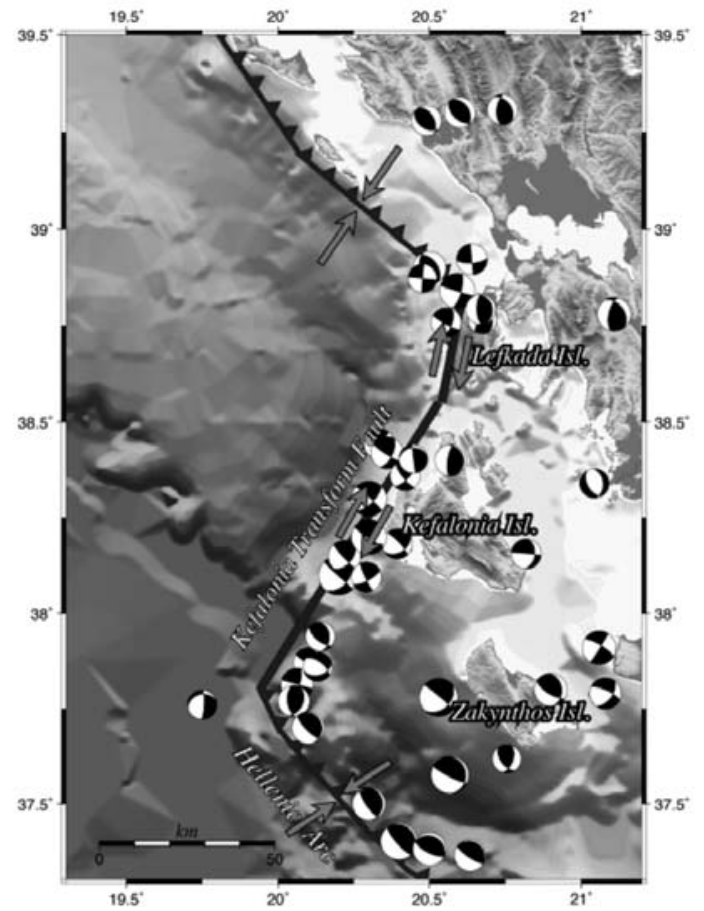

Fig. 1: Main active boundaries along with the fault plane solutions of strong events that occurred in the study area during the last four decades. Arrows show relative plate motion.

For the purpose of our study, which is firstly the determination of the properties of active structures in the area of Lefkada and Kefalonia Islands, we use data from the recently established network of three-component seismograph stations in these Islands to obtain the first reliable earthquake source parameter estimates for the region's microseismicity. We use the spatial distribution of seismicity and fault plane solutions to specify the properties of the major faults and further identify secondary active ones and to constrain their geometry and kinematics. In addition, for the whole area of central Ionian Islands, because of documented bias in routine analysis, we relocate larger earthquakes using the recordings of regional permanent networks. Recent seismicity over the last 45 years (1964-2008) defines bands of activity, increasing confidence in the geometry of the associated faults.

\section{Seismotectonic setting}

The area of central Ionian Islands, namely Lefkada and Kefalonia, constitutes the most active zone of shallow seismicity in the Aegean and its surroundings. This area is amongst the most active deforming ones in the Alpine - Himalayan belt, with its prominent feature the subduction of the eastern Mediterranean oceanic lithosphere under the Aegean (Comninakis \& Papazachos, 1971) along the Hellenic Arc. The seismic activity is very high throughout the arc, where thrust faulting dominates with the axis of maximum compression oriented NE-SW (Fig. 1). North of Lefkada Island a thrust faulting zone terminates, which runs along the south western coast of former Yugoslavia and continuous along the coastlines of Albania and north western Greek mainland, where the axis of maximum compression is almost perpendicular to the direction of the Adriatic-Ionian geologic zone. This zone resulted from the continental collision between the external Hellenides and the Adriatic microplate. 
Between continental collision to the north and oceanic subduction to the south, the Kefalonia - Lefkada dextral strike-slip fault system is developed, in accordance with the known relative motion between Aegean and eastern Mediterranean. The dextral strike-slip nature of this fault system was first recognized by Scordilis et al. (1985) who determined the fault plane solutions of the 1983 (M7.0) Kefalonia main shock and its largest aftershock (M6.3). This kind of faulting was further confirmed by waveform modelling for the 1983 main shock by Kiratzi \& Langston (1991) and for the 1972 Kefalonia earthquake (M6.3) by Papadimitriou (1993).

The area is of exceptional scientific interest from the seismotectonic point of view for several investigators. For the frequent strong events taking place there during the last five decades, waveform modelling has been accomplished (Papadimitriou, 1988; Kiratzi \& Langston, 1991; Papadimitriou, 1993; Baker et al., 1997) providing reliable fault plane solutions, which are depicted in Figure 1. In the same figure the main active boundaries are also shown along with arrows indicating relative plate motion. Papazachos et al. (1998) grouped the most reliable focal mechanisms and found a representative mechanism for Kefalonia with strike $=33^{\circ}$, dip $=56^{\circ}$ and rake $=163^{\circ}$, whereas for Lefkada the corresponding values are: strike $=11^{\circ}, \operatorname{dip}=60^{\circ}$ and rake $=165^{\circ}$.

Historical information and instrumental data reveal that the occurrence frequency for the stronger $(M \geq 6.5)$ events in the study area is almost constant during the last four centuries with one such shock per decade (Papadimitriou \& Papazachos, 1985). The maximum observed earthquake magnitude in Kefalonia equals to 7.4 and in Lefkada to 6.7 (Papazachos \& Papazachou, 2003). Moderate magnitude events are also very frequent, oftentimes located onshore, constituting an additional threat from the seismic hazard view point. It is then of importance to exploit the proper data that are available to us, aiming to define the geometric and kinematic properties of the active structures that have been activated and are possible candidates to host future moderate to strong events.

\section{Catalogue compilation of local earthquakes}

\subsection{Local network operation}

A portable seismic network was deployed in the study area consisting of seven 3-component digital stations equipped with broad-band (30s) and short period $(1 \mathrm{~Hz})$ sensors, all equipped with GPS antenna for timing. These stations operated in continuous mode since the middle of 2007 with a sampling frequency of 125 samples/sec. The spacing between stations varied between 5 to $10 \mathrm{~km}$, allowing accurate earthquake locations (red squares in Fig. 2). In addition to the recordings of the local network, data from the stations of the national regional seismological network, installed on the two islands (blue diamonds in Fig. 2), are also available for our study.

\subsection{Focal parameters determination}

For the earthquakes hypocentral determination the HYPOINVERSE (Klein, 2002) computer program was used, for which in addition to the arrival times of the seismic waves at the seismological stations, an accurate velocity model is needed. We adopted the $1-\mathrm{D}$ velocity model and a velocity ratio of $\mathrm{V}_{\mathrm{p}} / \mathrm{V}_{\mathrm{s}}=1.80$ proposed by Haslinger et al. (1999) for a broader area that the one of the present study.

The accuracy in the hypocentral determination was checked by the distribution of the errors in the determination of the occurrence time (rms), the epicentral coordinates (erh) and the focal depth (erh). As it can be seen from Figure 3a, all rms values are smaller than $0.5 \mathrm{sec}$, with the 

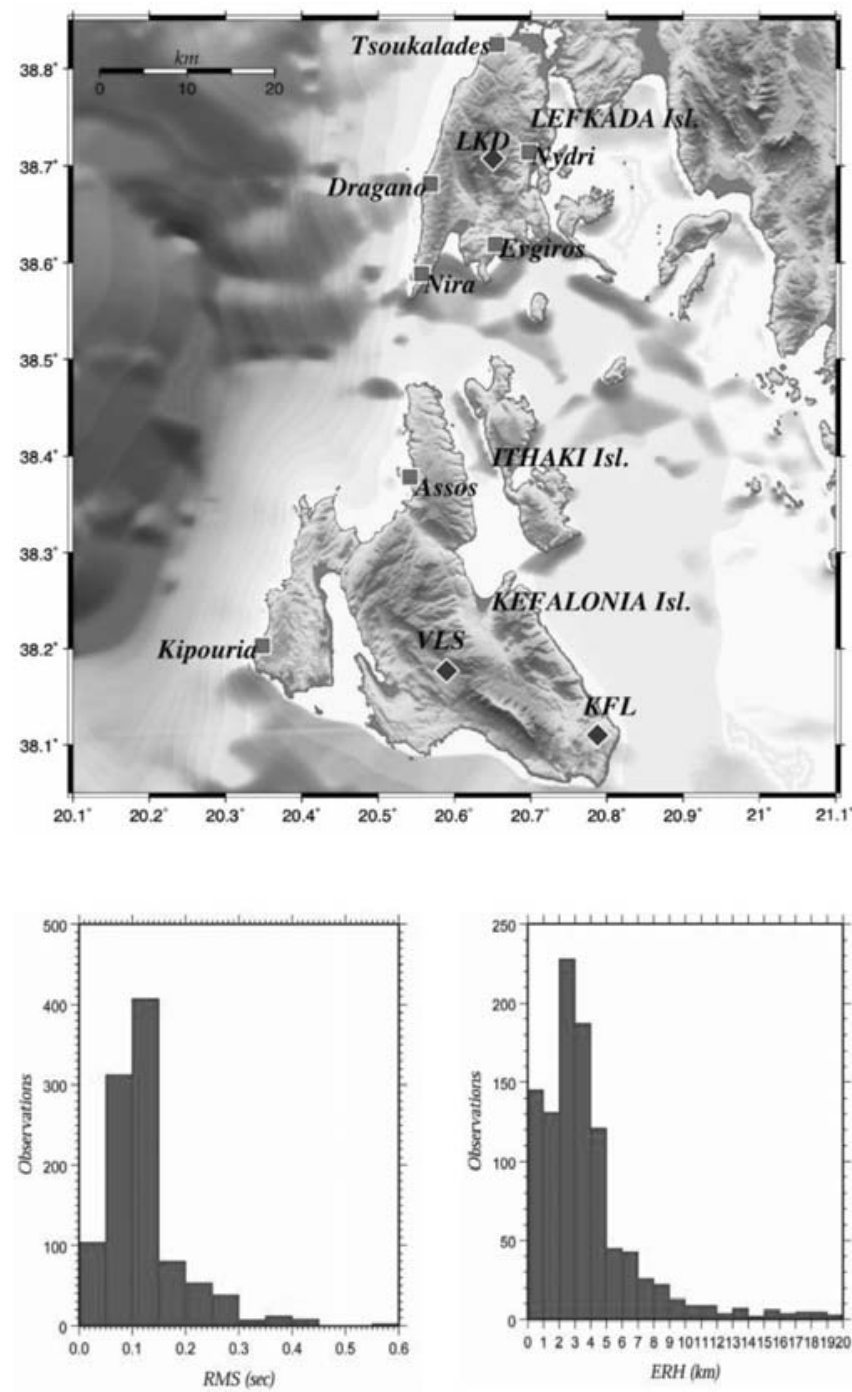

(a)

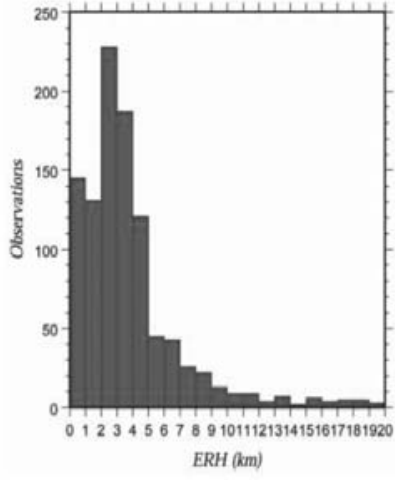

(b)
Fig. 2: The locations of the stations of the local seismological network (red rectangles), along with the permanent ones (blue diamonds) of the national seismological network.

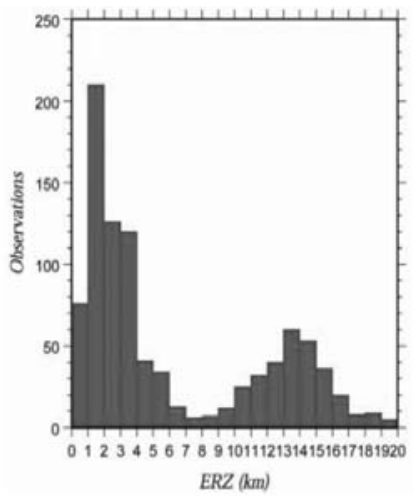

(c)

Fig. 3: Histograms of the (a) root mean square in the occurrence time (rms), (b) epicentral determination error (erh) and (c) depth determination error (erz), of local events locations.

vast majority being less than $0.2 \mathrm{sec}$. The errors in the epicentral determination are mostly less than $10 \mathrm{~km}$, with the $80 \%$ of them being less than $5 \mathrm{~km}$ (Fig. 3b). The maximum in this distribution appears at $3-4 \mathrm{~km}$, with $25 \%$ of the events assigned an erh $<3 \mathrm{~km}$. The errors in focal depth determination are less of $20 \mathrm{~km}$, with most of these values being less than $7 \mathrm{~km}$ and the maximum at the range $0-4 \mathrm{~km}$ (fig. $3 \mathrm{c}$ ). This distribution exhibits two clusters, in the range of 0-7 km and 8-20 km, respectively. This second cluster can be attributed to the limited number of observations of the lower magnitude events as well as to the fact that a significant portion of the activity occurred outside the local network. 


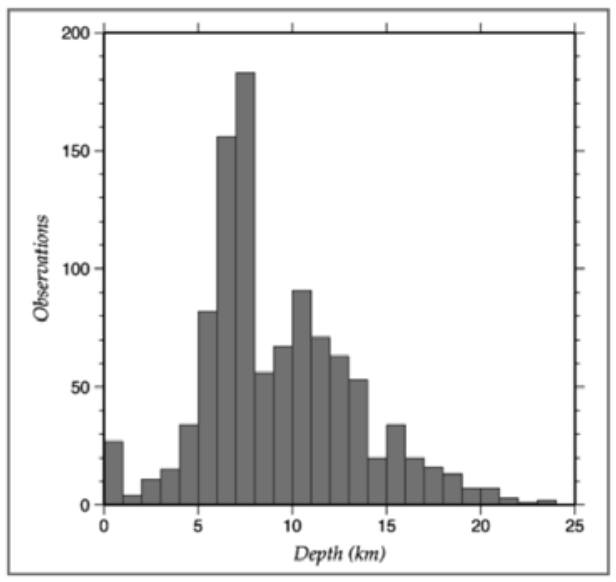

(a)

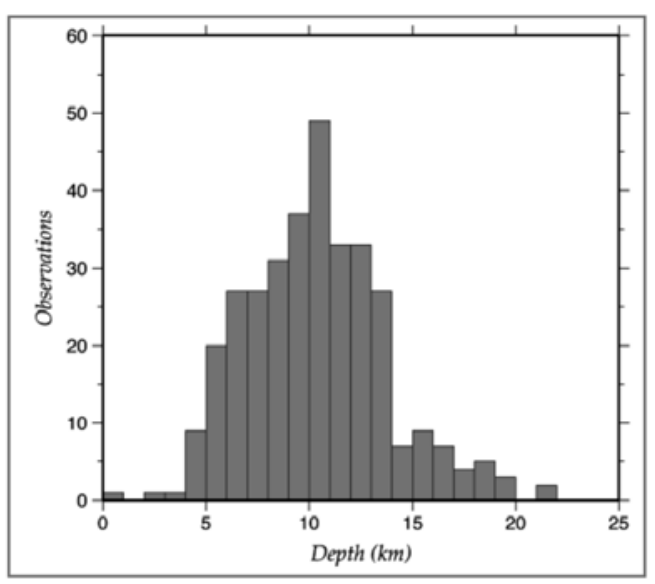

(b)

Fig. 4: Focal depths distribution of (a) all the events that occurred in the study area during the period covered by our data, and (b) the best located events.

Earthquake magnitudes were estimated from the maximum amplitude of the recordings at each seismological station. For this purpose simulation filters were used, which transformed the recordings of a sensor (preferentially broad band) to Wood Anderson recording, provided that the transfer function permits this transformation. Magnitudes were estimated from the maximum amplitudes at the two horizontal components of each station of the local network, after transformation, and the mean value was adopted as the assigned magnitude of each event.

\subsection{Distribution of focal depths}

The knowledge of the depth distribution provides valuable information on the geometry of the active structures. In tectonically complex areas, like the area of central Ionians, this information is unambiguously necessary. The focal depths of all the events recorded by the local network are between 0 and $24 \mathrm{~km}$, with the vast majority of them between 4 and $16 \mathrm{~km}$ (Fig. 4a). It must be noted here that in this data sample events that were recorded by a small number of stations or located far from the local network, are also included. The depth distribution of the best located events $(\mathrm{rms} \leq 0.2 \mathrm{sec}$, erh $\leq 2.0 \mathrm{~km}$, erz $\leq 2.0 \mathrm{~km})$ is depicted in Figure $4 \mathrm{~b}$, which reveals that the seismogenic layer extends between 4 and $15 \mathrm{~km}$, with a maximum of activity at $10-11 \mathrm{~km}$ depth.

\subsection{Fault plane solutions determination}

The onsets of at least six first arrivals of the P waves at the seismological stations and the FPFIT (Reasenberg \& Oppenheimer, 1985) computer program were used for the focal mechanisms determination. Since the quality of the solutions depends on factors such as the azimuthal coverage as well as the distribution of the arrivals on the projection plane, reliable fault plane solutions were feasible for a limited number of events. These reliable solutions are exploited for the definition of the properties of the active structures and are presented in a later section. 


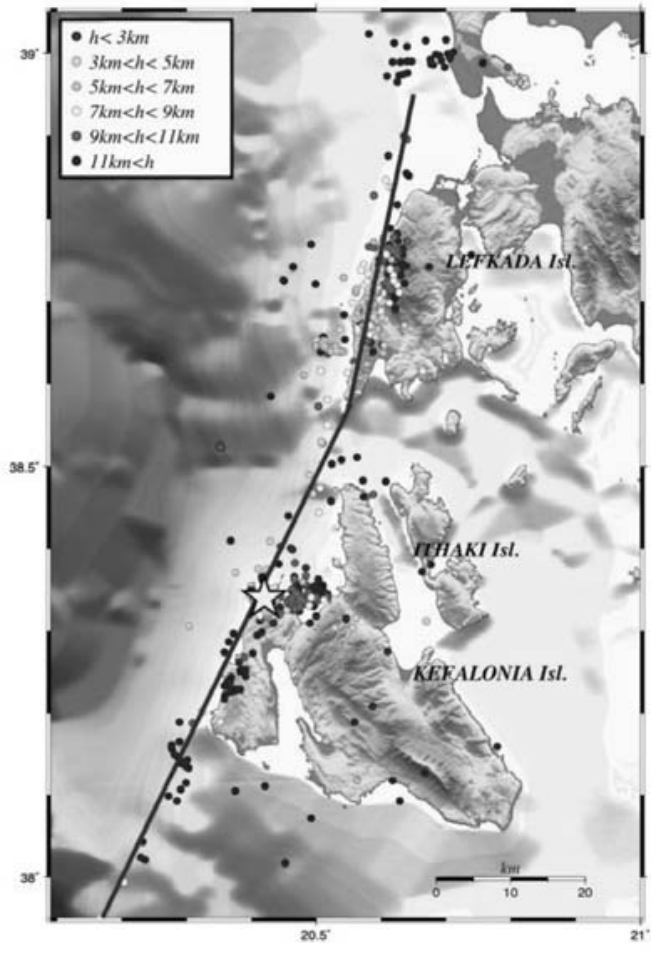

Fig. 5: Spatial distribution of the best located local events, along with the trace of the Kefalonia - Lefkada fault system trace.

\section{Properties of the active structures}

\subsection{Spatial distribution of the seismic activity}

Figure 5 depicts the epicentral distribution of the best located events (rms $\leq 0.2 \mathrm{sec}$, erh $\leq 2 \mathrm{~km}$, erz $\leq 2 \mathrm{~km}$ ), along with the trace of the dextral strike-slip active boundary of the Kefalonia Lefkada fault system. It must be noted here that this activity is not representative for the whole area, but only for the part with adequate network coverage. It is observed that most activity is narrowed along the western coastlines of Lefkada and the north western coastline of Kefalonia. The activated area in Lefkada coincides with the aftershock area of the 2003 strong (M6.2) main shock (Karakostas et al., 2004). It then provides strong evidence that this structure is appreciably active.

In the area of Kefalonia where increased activity appeared, an M5.9 event occurred on March 27, 2007. The epicentre of this main shock is shown with an asterisk in Figure 5 and is located with data from the national regional network, because the local network installed a couple of weeks later. Since this occurrence the activity continued with a high rate as far as moderate and smaller magnitude events concerns, many of them felt in the nearby villages. Continuous activity is also present along the western peninsula, which extends along the south western offshore area.

Figure 6 exhibits a cross section parallel to the strike of the fault system, as this is traced in Figure 5. This figure evidences two main clusters, the one at the area of the 2007 seismic excitation and the second one at the central part of Lefkada Island. It is also prominent that the focal depths are concentrated between 4 and $15 \mathrm{~km}$, while larger depth concentrations concern earthquakes occurred outside the local network with probably larger uncertainty in the depth determination. 


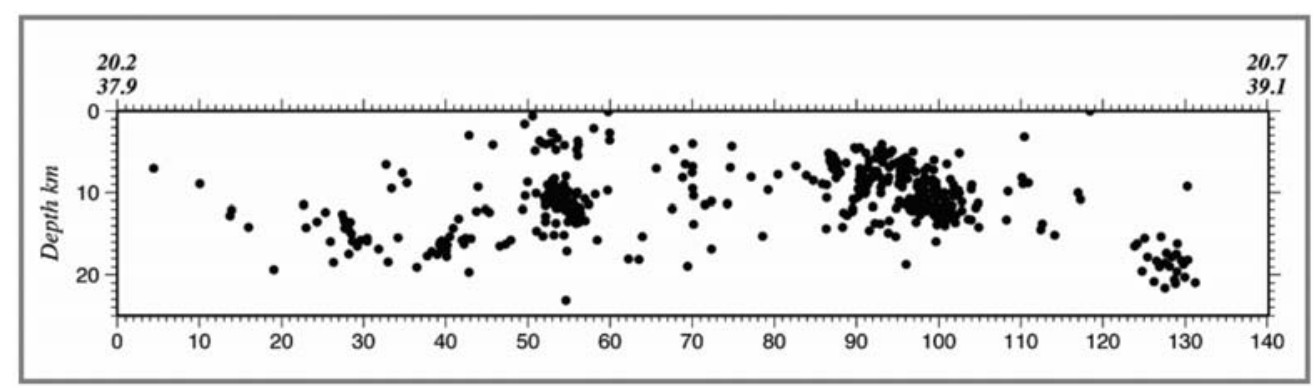

Fig. 6: Cross section parallel to the line defined by $37.9^{\circ}-20.2^{\circ}$ and $39.1^{\circ}-20.7^{\circ}$, almost parallel to the strike of the Kefalonia - Lefkada fault system.

\subsection{Microseismicity in Lefkada Island}

Figure $7 \mathrm{a}$ depicts the best located earthquakes along with the high quality determined fault plane solutions as lower hemisphere equal area projections. The reason we use the chosen data is because the definition of the geometry and kinematics of the active structures demands the most accurate data sample. In addition to the seismic zone striking NNE-SSW, along the main tectonic structure, two more distinctive clusters are apparent, which in turn prefigure two secondary active structures. The first is located offshore the south western coastline, strikes at WNW-ESE, in full accordance with the fault plane solutions of five events of this cluster. This strike, implying left-lateral strike-slip motion, supports the characterization of this structure as a conjugate one of the dominant NNE-SSW dextral strike slip motion. Although the occurrence of a strong or moderate earthquake there is not known there, its length is capable to accommodate an event of M5.5.

The second active structure revealed by the local data is located in the central western onshore part of the Island. It strikes at NNW-SSE, in agreement with four fault plane solutions of events encompassed in this cluster. With a length of $7 \mathrm{~km}$, it can be associated with an event of M5.5. It was the most active structure during the operation of the local network, partially due to the fact that this location was well azimuthally covered by local stations. It is worth to note that this structure was also activated during the 2003 seismic sequence, and severe damage to the natural and built environment was reported. Although such macroseimic effects were expected along the west coastline where the main rupture took place (Karakostas, 2008), the severity of damage at this particular place evidenced the activation of secondary faults.

\subsection{Microseismicity in Kefalonia Island}

The best located events that occurred in the area of Kefalonia are shown in Figure 7b, and mainly form two clusters, the first one in Palliki peninsula (west part of the Island) and the second at the Gulf of Myrtos (north western part of Island). The spatial epicentral concentration of the first cluster is not adequate to reveal the properties of the structure that host this data set. An adequate number of fault plane solutions, however, and the consistency among these solutions, support a NNE-SSW striking thrust faulting. Even though this kind of faulting is first suggested here, its kinematics is consistent with the local stress field (almost E-W orientation of the maximum compression axis, in agreement with the strong events fault plane solutions depicted in Figure 1). 


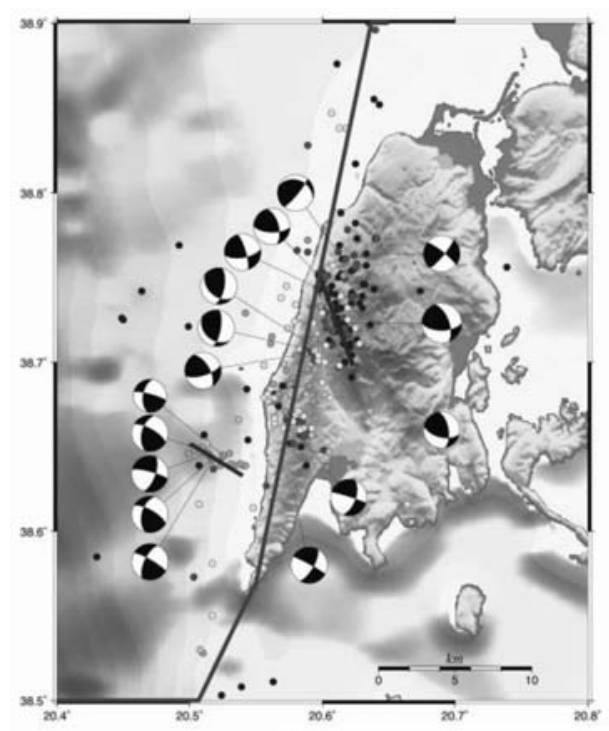

(a)

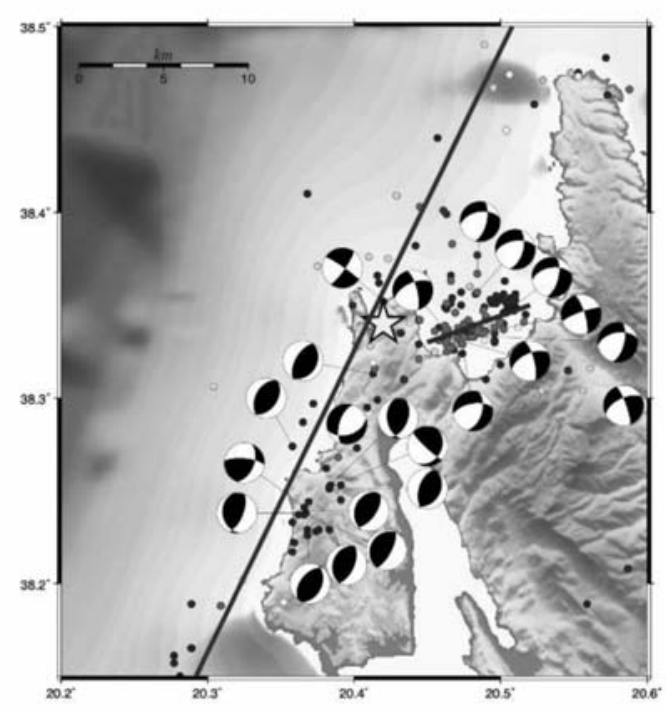

(b)

Fig. 7: (a) Spatial distribution of best located local microseismicity in Lefkada area along with fault plane solutions determined for some of these events, shown as lower hemisphere equal area projections. (b) Spatial distribution of best located local microseismicity in Kefalonia area along with fault plane solutions determined for some of these events, shown as lower hemisphere equal area projections.

A very energetic seismic sequence followed the 2007 main shock in the Gulf of Myrtos, to the north western offshore area of Kefalonia, where both the epicentral distribution and fault plane solutions of an adequate number of events, reveal a structure of 5-6 km in length, striking at ENE-WSW, and exhibiting oblique faulting.

\section{Relocation of the regional catalogue}

\subsection{Regional data collection}

The relocation of the events that occurred in an area broader than the one covered by the local network, which accommodates the highest activity of Greece and its surroundings, during 1964April 2008 was attempted. In order to achieve high relocation accuracy, an adequate number of body waves (both $\mathrm{P}$ and $\mathrm{S}$ ) recordings, at the seismological stations of the broader area, for each earthquake were seeking. For the interval 1964-May 2006 data were taken mainly from the International Seismological Center (ISC, http://www.isc. ac.uk). For the interval June 2006-April 2008 the phases collected at the Seismological Station of Geophysics Department, of the Aristotle University of Thessaloniki. Data were gathered from 745 seismological stations in total.

\subsection{Focal parameters determination}

For the hypocentral relocation an attempt was made to define a regional velocity model for the study area, based on the recordings of the permanent seismological network. The derived model agreed satisfactorily with the one proposed by Haslinger et al. (1999) for the area of Ionian Islands and north western Greek mainland. Therefore, this latter model was finally used after 


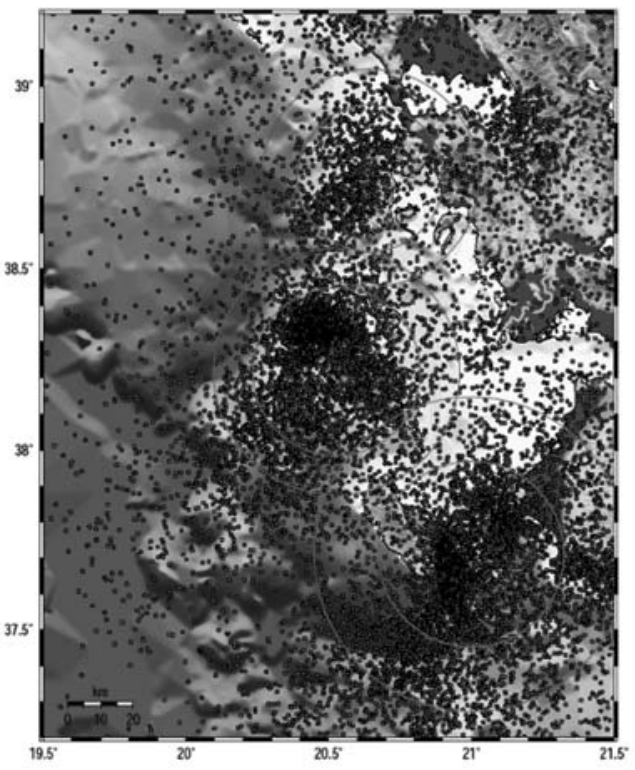

(a)

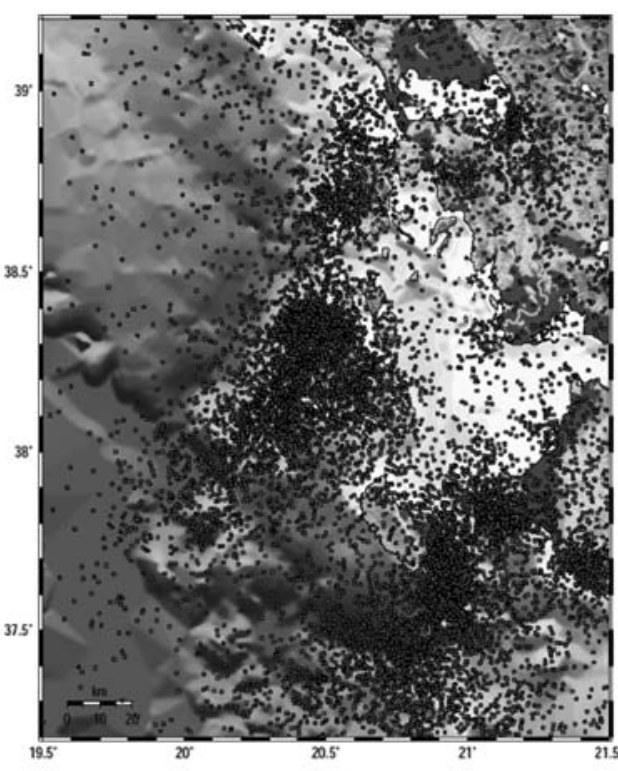

(b)

Fig. 8: (a) Spatial distribution of regional seismicity upon which the three regions were defined for the application of HYPOINVERSE computer program. (b) Spatial distribution of the relocated earthquakes that occurred in the area of Lefkada, Kefalonia and Zakynthos Islands during $1964-08 / 04 / 2008$.

confirming its appropriateness for the certain area. Since this model was one dimensional, and in order to take into account lateral crustal inhomogeneities, time delays were estimated for each seismological station. The HYPOINVERSE (Klein, 2002) computer program was applied and the initial relocation resulted to 13041 preliminary determined hypocenters.

\subsection{Estimations of stations residuals}

For the estimation of time delays, that is the difference between the theoretical and the observed travel time from the earthquake focus to the seismological station, the area of interest was separated into three subareas on the basis of epicentral concentration (Fig. 8a). For the station residuals estimation in each subarea, the earthquakes with an adequate number of recordings were taken into account. For Lefkada and Kefalonia areas in particular, the focal parameters of the local events were also considered, whereas for Zakynthos the best available data based on the recordings of the permanent network. The station delays were estimated separately for each subarea and each seismological station, because the ray paths are different. Thus, in each subarea individual sets of station delays were estimated and used for the relocation.

\subsection{Determination of focal parameters}

After detailed elaboration of the available data and station delays, the hypocentral relocation was accomplished. From the errors distribution in the determination of the occurrence time (rms), epicentral coordinates (erh) and focal depth (erz), it is observed that more than the $60 \%$ of the relocated events exhibit rms errors less than $0.8 \mathrm{sec}$, whereas more than $50 \%$ exhibit erh 
and erz less than $5 \mathrm{~km}$ and $8 \mathrm{~km}$, respectively. The epicentral distribution of the relocated events is depicted in Figure $8 \mathrm{~b}$.

A significant reduction in the scatter of epicentral distribution is observed, which in combination with independent fault information furnishes important contribution to the configuration of the regional active structures. A particular case is the aftershock area of the 1983 strong main shock (M7.0), which occurred in the southwest offshore area of Kefalonia Island. The delineation of aftershock epicentres is evident in Figure 8b, It is worth to mention here that whereas the formal errors in the relocated seismicity are satisfactorily accurate, errors resulted from faults misassociation can be larger.

\section{Conclusions}

The microseismicity recorded by the local network installed and operated in the area of central Ionian Islands, provided the means of identifying secondary active structures and their geometric and kinematic properties. The particular structures although of smaller lengths than the ones associated with the stronger events $(M \geq 6.0)$ in this region, are capable to accommodate moderate events $(5.0 \leq \mathrm{M} \leq 5.9)$. For this reason they must be taken into consideration in the future seismic hazard assessment studies, in particular because they are located onshore and near to the built environment. It must be mentioned here that the 1994 M5.4 Lefkada earthquake, produced considerable damage in the villages of the north western part of the Island. The exploitation then of the microseismicity for the identification of active structures and definition of their properties, is necessitated for a seismotectonically complex area, like the area of central Ionian Islands.

\section{Acknowledgments}

This work was partially supported by the Local Union of Lefkada Island Municipalities. The GMT system (Wessel and Smith, 1998) was used to plot the figures. Geophysics Department contribution 754 .

\section{References}

Baker, C., Hatzfeld, D., Lyon-Caen, H., Papadimitriou, E. and Rigo, A., 1997. Earthquake mechanisms of the Adriatic Sea and western Greece: implications for the oceanic sudbuction - continental collision transition. Geophysical Journal International, 131, 559-594.

Haslinger, F., Kissling, E., Ansorge, J., Hatzfeld, D., Papadimitriou, E., Karakostas, V., Makropoulos, K., Kahle, H.-G. and Peter, Y. (1999). 3D crustal structure from local earthquake tomography around the gulf of Arta (Ionian region, NW Greece). Tectonophysics, 304, 201-218.

International Seismological Center, 2001. On-line Bulletin, http://www.isc.ac.uk/ Bull, International Seismological Center, Thatcham, United Kingdom.

Karakostas,V., 2008. Relocation of aftershocks of the 2003 Lefkada sequence: Seismotectonic implications Proc. $3^{\text {rd }}$ Hellenic Conf. Earthquake Engineering \& Engineering Seismology, Athens 5-7 Nov. 2008, CD ROM, pp.16.

Karakostas, V. G. and Papadimitriou, E. E., 2010. Fault complexity associated with the 14 August $2003 \mathrm{M}_{\mathrm{w}} 6.2$ Lefkada, Greece, aftershock sequence. Acta Geophysica, 58, doi: 10.2478/s11600010-0009-6.

Karakostas, V. G., Papadimitriou, E. E. and Papazachos, C. B., 2004. Properties of the 2003 Lefkada, 
Ionian Islands, Greece, earthquake seismic sequence and seismicity triggering, Bulletin Seismological Society America, 94, 1976-1981.

Kiratzi, A. A. and Langston, C., 1991. Moment tensor inversion of the January 17, 1983 Kefallinia event of Ionian Islands. Geophysical Journal International, 105, 529-535.

Klein, F. W., 2002. User's Guide to HYPOINVERSE-2000, a Fortran program to solve earthquake locations and magnitudes. U. S. Geol. Surv. Open File Report 02-171 Version 1.0.

McClusky, S., Balassanian, S., Barka, A., Demir, C., Georgiev, I., Hamburger, M., Hurst, K., Kahle, H., Kastens, K., Kekelidze, G., King, R., Kotzev, V., Lenk, O., Mahmoud, S., Mishin, A., Nadariya, M., Ouzounis, A., Paradisis, D., Peter, Y., Prilepi, M., Reilinger, R., Sanli, I., Seeger, H., Tealeb, A., Toksoz, M. N. and Veis, G., 2000. GPS constraints on crustal movements and deformations in the Eastern Mediterranean (1988-1997): Implications for plate dynamics. Journal Geophysical Research, 105, 5695-5719.

Papadimitriou, E. E., 1993. Focal mechanism along the convex side of the Hellenic Arc and its tectonic significance. Bolletino Geofisica Teorica Applicata, 35, 401-426.

Papadimitriou, E. E. and Papazachos, B. C., 1985. Evidence for precursory seismicity patterns in the Ionian Islands (Greece). Earthquake Prediction Research, 3, 95-103.

Papadimitriou, P., 1988. Etude de la structure du manteau superieur de l' Europe et Modelisation des ondes de volume engendrees par des seismes Egeens. These de Doctorat, Univ. Paris VII, France, 1988.

Papazachos, B. C. and Comninakis, P. E., 1971. Geophysical and tectonic features of the Aegean arc. Journal Geophysical Research, 76, 8517-8533.

Papazachos, B. and Papazachou, K., 2003. The earthquake of Greece, Ziti Publications, pp. 317.

Papazachos, B. C., Papadimitriou, E. E., Kiratzi, A. A., Papazachos, C. B. and Louvari, E. K., 1998. Fault plane solutions in the Aegean Sea and the surrounding area and their tectonic implications. Bolletino Geofisica Teorica Applicata, 39, 199-218.

Papazachos, C. B., 1999. Seismological and GPS evidence for the Aegean-Anatolia interaction. Geophysical Research Letters, 26, 2653-2656.

Scordilis, E. M., Karakaisis, G. F., Karakostas, B. G., Panagiotopoulos, D. G., Comninakis, P. E. and Papazachos, B. C., 1985. Evidence for transform faulting in the Ionian Sea: The Cephalonia Island earthquake sequence. Pure Applied Geophysics, 123, 388-397.

Reasenberg, P. and Oppenheimer, D., 1985. FPFIT, FPPLOT and FPPAGE: Fortran programs for calculating and displaying earthquake fault plane solutions. U.S. G.S., Open-File Report, 95-515, $24 \mathrm{pp}$.

Wessel, P. and Smith, W. H. F., 1998. New, improved version of the Generic Mapping Tools Released. EOS Trans. AGU, 79, 579. 